\title{
Paul Cristophe, George Sand et Jésus, une inlassable recherche spirituelle
}

Anne Chevereau

\section{(2) OpenEdition}

\section{Journals}

Édition électronique

URL : http://journals.openedition.org/studifrancesi/36462

DOI : 10.4000/studifrancesi.36462

ISSN : 2427-5856

Éditeur

Rosenberg \& Sellier

\section{Édition imprimée}

Date de publication : 1 juillet 2005

Pagination : 187-188

ISSN : 0039-2944

\section{Référence électronique}

Anne Chevereau, «Paul Cristophe, George Sand et Jésus, une inlassable recherche spirituelle », Studi Francesi [En ligne], 145 (XLIX | I) | 2005, mis en ligne le 30 novembre 2015, consulté le 18 avril 2021. URL : http://journals.openedition.org/studifrancesi/36462 ; DOI : https://doi.org/10.4000/ studifrancesi.36462 


\title{
Paul Cristophe, George Sand et Jésus, une inlassable recherche spirituelle
}

\author{
Anne Chevereau
}

\section{RÉFÉRENCE}

PAUL CRISTOPHE, George Sand et Jésus, une inlassable recherche spirituelle, Paris, Éditions du Cerf, 2003, pp. 214.

1 L'auteur, professeur d'histoire religieuse, a découvert, par un ami prêtre, de 1970 à 1980, le Berry de George Sand. Séduit par la personnalité de la romancière, il a poussé sa recherche à travers la Correspondance - Georges Lubin n'avait publié alors que 12 volumes - Histoire de ma Vie, les biographies (Maurois, Mallet entre autres) et les romans disponibles à l'époque. Il paraît ignorer l'étude de Maria Grazia Fulvi Cittadini, parue in George Sand et son temps. Hommage à Annarosa Poli, Genève, Slatkine / Moncalieri, C.I.R.V.I., t. III, pp. 1351-1365). Ce travail de patiente compilation lui a permis de rédiger en 1977 un très long article sur George Sand; L'Évangile et Jésus, paru dans le numéro spécial du Centenaire des Facultés catholiques de Lille.

$2 \mathrm{Au}$ fur et à mesure de la parution de la Correspondance, de la publication par Les Introuvables des éditions épuisées de George Sand, et des nouvelles études et biographies, Paul Christophe a complété son travail initial pour ce George Sand et Jésus. Collationnant les témoignages à travers l'œuvre de l'écrivain, il conduit le lecteur sur son cheminement spirituel qui atteint vers la fin de sa vie un modernisme proche du catholicisme du XXe siècle: George ne rêve-t-elle pas de la tenue d'un Concile? (Le Temps, 12 septembre 1872, doc. 45).

3 Éduquée par une grand-mère déiste et voltairienne, face à un clergé des paroisses voisines à la formation théologique étroite, incapable de la guider, cette petite fille est vite précoce grâce à des lectures non contrôlées par son aïeule. Au couvent, âgée de 15 ans, Aurore connait une extase mystique: «Je sentis enfin cette communication s'établir soudainement comme si un obstacle invincible se fût abîmé entre le foyer d'ardeur 
infinie et le feu assoupi dans mon âme». (0A, I-914). Obligée un an plus tard de regagner Nohant, Aurore retrouve une forme de solitude morale et sa foi est encore trop fragile pour être préservée dans le milieu agnostique où elle est amenée à vivre désormais.

Un mariage manqué, se terminant par une séparation légale, une liberté acquise de haute lutte, une réussite littéraire foudroyante, des faux-pas sentimentaux décevants ont définitivement éloigné George de toute pratique culturelle, mais, comme l'écrit Maurois, «ce qui surnageait en cette âme houleuse, c'était malgré tant de naufrages, le besoin de croire à l'amour et peut-être à l'amour divin». À Charles d'Aragon, elle affirme porter en elle un trésor que personne ne peut lui enlever: la foi morale et religieuse (Corr, III, p. 246).

George, influencé par Liszt, rencontre Lamennais en 1835. Il ne sera pas longtemps son guide, bien qu'il lui ait rendu l'espérance, après une période d'amer scepticisme. En 1836, lui succède Pierre Leroux: le philosophe influence longtemps son oeuvre, en particulier Spiridion, «livre que l'auteur consacre à sa passion pour un problème religieux» (p. 63). George refuse la divinité de Jésus et espère que l'avenir restitue sa véritable grandeur, «celle d'avoir été vraiment le fils de la femme et le sauveur, c'est-àdire l'âme de l'humanité, le prophète de l'idéal George Sand réduit Jésus à n'être plus qu'un maillon, sans doute exceptionnel dans le progrès de l'humanité» (p. 67). Jésus est donc un «homme vénérable et adorable dont nous avons fait par idolâtrie un membre de la Trinité divine... Il n'a pas réglé le sort de l'humanité sur la terre. Il ne pouvait pas, il n'était pas Dieu. Mais il m'en a assez dit pourtant pour que je l'adore autant qu'il est permis d'adorer un homme, pour que je comprenne la voie où il faut marcher... il m'exalte cet homme divin!» (p. 68).

Outre le refus de la divinité de Jésus, George Sand récuse aussi le dogme «abominable» d'un châtiment éternel qui défigure le visage de Dieu: «Moi, j'ai l'espoir d'être sauvée tout comme un autre» (Corr, VI, p. 830). Elle rejette la présence réelle dans l'Eucharistie, comme jumelée avec le dogme de la divinité du Christ. En 1848, posant la question de savoir ce que sera le «dogme de la France», George Sand affirme que «le dogme catholique n'existe plus... mais l'idée chrétienne subsiste. L'esprit de Jésus, cet esprit vraiment divin est entré en nous en même temps qu'il se retirait de l'Eglise. L'Evangile s'est réfugié dans le cœur du pauvre» (p. 87). «C'est sur la personne de Jésus que s'est concentré l'intérêt de George Sand. Elle voit en Jésus la plus noble et la plus pure manifestation de l'amour universel parmi nous» (p. 147).

7 À la question «Peut-on dire qu'elle est restée chrétienne?», Paul Christophe répond que «c'est sans doute un esprit chrétien qui l'anime lorsque, inlassablement, elle reprend à son compte la question de Jésus qui la fascine toujours: «Pour vous qui suis-je?» (p. 148). 